\title{
Increased Susceptibility to Induction of Long-Term Depression and Long-Term Potentiation Reversal during Aging
}

\author{
Christopher M. Norris, Donna L. Korol, and Thomas C. Foster \\ Department of Psychology and the Neurosciences Graduate Program, University of Virginia, \\ Charlottesville, Virginia 22903
}

\begin{abstract}
Homosynaptic long-term depression (LTD) and reversal of longterm potentiation (LTP) were examined extracellularly at CA3-CA1 synapses in stratum radiatum of slices from adult (6-9 months) and aged (20-24 months) Fischer 344 rats. Prolonged lowfrequency stimulation (LFS) $(900$ pulses/1 Hz) of the Schaffer collaterals depressed the initial slope of the excitatory postsynaptic potential (EPSP) in aged but not adult rats. LTD at aged synapses was pathway-specific, persistent, and sensitive to the NMDA receptor antagonist DL-2-amino-5-phosphonopentanoic acid (AP5). Adult slices exhibited AP5-sensitive LTD in high $\left[\mathrm{Ca}^{2+}\right]$ medium, whereas LTD in aged slices was blocked by high $\left[\mathrm{Mg}^{2+}\right]$, suggesting that differences in $\mathrm{Ca}^{2+}$ regulation may underlie susceptibility to LTD.

Despite age-related differences in LTD induction, no age difference in LTP magnitude was revealed. Additionally, LFS
\end{abstract}

delivered $60 \mathrm{~min}$ after LTP induction resulted in similar LTP reversal for both age groups. Susceptibility differences to LTP reversal were indicated after multiple short-duration LFS bursts (30 pulses $/ 1 \mathrm{~Hz}$ ), with each burst separated by $10 \mathrm{~min}$. Aged synapses exhibited significant reversal after a single burst and complete reversal after three LFS episodes. In adult slices, LTP reversal appeared after the fourth burst, and at no time was LTP depressed to initial baseline levels. This study provides the first characterization of homosynaptic LTD/LTP reversal in the aged animal and demonstrates that one form of plasticity, depression attributable to LFS, is increased during aging.

Key words: long-term depression; aging; synaptic plasticity; hippocampus; CA1; Fischer 344
During normal aging, the hippocampal formation undergoes changes that might contribute to age-related differences in synaptic function and behavior (Geinisman et al., 1995). Among these changes are reduced synaptic strength in area CA1 and the inability to maintain synaptic potentiation (Landfield et al., 1978; Barnes et al., 1992; Moore et al., 1993). Alterations in processes that influence synaptic strength may underlie age-related memory deficits (Barnes et al., 1994). For example, the decay rate for long-term potentiation (LTP), a neural model of memory, is accelerated during aging, and differences in decay rate between aged and adult rats are similar to differences in the forgetting rate on a spatial memory task (Barnes and McNaughton, 1985).

One explanation for rapid LTP decay is that aged animals lose the capacity to actively maintain synaptic enhancement. This idea implies that aged animals are lacking in specific mechanisms, such as protein synthesis, which mediate LTP persistence (Frey et al., 1988; Otani et al., 1989). Alternatively, the increased decay rate may reflect augmented mechanisms for actively depressing potentiated synapses. Under this hypothesis, the capacity for expressing durable potentiation is intact in the aged hippocampus but obscured by other processes that are altered during aging. A candidate process for regulating LTP duration is long-term synaptic depression (LTD) (Bear and Malenka, 1994; Linden and Connor, 1995).

Recently, a reliable protocol for inducing homosynaptic LTD in

\footnotetext{
Received May 13, 1996; accepted June 14, 1996.

This work was supported by National Institutes of Health Grants NS31830 to T.C.F. and GM08328-04 to C.M.N. We thank Julie Lichtenvoort, Heather Fugger, and Dr. Nicholas Waters for their editorial comments.

Correspondence should be addressed to Dr. Thomas C. Foster, Department of Psychology, University of Virginia, Charlottesville, VA 22903.

Copyright (C) 1996 Society for Neuroscience 0270-6474/96/165382-11\$05.00/0
}

vitro using low frequency stimulation (LFS, 1-3 Hz) has been developed (Dudek and Bear, 1992; Mulkey and Malenka, 1992). This form of LTD is especially robust in neonates and is modest in amplitude or nonexistent in mature animals (Dudek and Bear, 1993; Wagner and Alger, 1995). LFS, however, reliably depresses adult synapses that have recently undergone LTP (Barrionuevo et al., 1980; Staubli and Lynch, 1990; Fujii et al., 1991; Dudek and Bear, 1993; Wexler and Stanton, 1993; O’Dell and Kandel, 1994; Wagner and Alger, 1995). The results indicate that susceptibility to synaptic depression can vary according to maturational factors and the history of synaptic activity.

Relative to that in adults, LTP magnitude decays rapidly in CA1 during the first two postnatal weeks (Harris and Teyler, 1984; Muller et al., 1989; Jackson et al., 1993). As noted, LTD magnitude is also most robust during this time period. If susceptibility to LTD contributes to LTP decay, then aged synapses may also exhibit increased susceptibility to LTD induction. Heterosynaptic LTD has been reported in the dentate gyrus of aged rats (Pang et al., 1993), indicating that at least one form of synaptic depression can be observed in the aged animal.

The goal of the present research was to examine susceptibility to homosynaptic depression in CA1 during aging. This report demonstrates that susceptibility to LTD and LTP reversal is greater in aged than in adult rats. Furthermore, age-related differences in LTD induction could be altered by manipulating the extracellular $\mathrm{Ca}^{2+} / \mathrm{Mg}^{2+}$ ratio, consistent with the idea that changes in $\mathrm{Ca}^{2+}$ regulation with advanced age underlie increased susceptibility. The findings have important implications concerning the manner in which synaptic strength is regulated during aging. 
Parts of this paper have been published previously (Norris and Foster, 1995).

\section{MATERIALS AND METHODS}

Adult (6-9 months) and aged (20-24 months) male Fischer 344 rats were obtained from the National Institute of Aging's colony at Harlan. All animals were maintained on a $12 \mathrm{hr}$ light/dark cycle and had access to food and water ad libitum.

Rats were anesthetized deeply with methoxyflurane and then decapitated. Brains were removed rapidly and stored briefly in chilled, oxygenated $\left(95 \% \mathrm{O}_{2} / 5 \% \mathrm{CO}_{2}\right)$ artificial cerebrospinal fluid (ACSF) before hippocampi were dissected away. Hippocampal slices (450-500 $\mu \mathrm{m})$, cut parallel to the alvear fibers, were prepared with a gravity-controlled tissue chopper and transferred to a standard interface recording chamber, aerated with a $95 \% \mathrm{O}_{2} / 5 \% \mathrm{CO}_{2} \mathrm{mix}$, and perfused continuously (1-1.5 $\mathrm{ml} / \mathrm{min}$ ) at $30-32^{\circ} \mathrm{C}$ with oxygenated ACSF that contained (in $\mathrm{mM}$ ): 124 $\mathrm{NaCl}, 2 \mathrm{KCl}, 1.25 \mathrm{~K}_{2} \mathrm{PO}_{4}, 2 \mathrm{MgSO}_{4}, 2 \mathrm{CaCl}_{2}, 26 \mathrm{NaHCO}_{3}, 10$ dextrose, $\mathrm{pH} \approx 7.4$. Slices were permitted to equilibrate for at least $1 \mathrm{hr}$ before stimulation, and recordings were initiated. In some experiments, either the extracellular $\left[\mathrm{Ca}^{2+}\right]$ or $\left[\mathrm{Mg}^{2+}\right]$ was raised to $4 \mathrm{mM}$ and/or DL-2-amino5-phosphonopentanoic acid (AP5) (Sigma, St. Louis, MO) was added to the bath.

CA3-CA1 synapses were activated with a bipolar stimulating electrode (two insulated platinum-iridium wires, twisted together with tips exposed) located in the stratum radiatum of area CA1 at or near the CA3 border. For certain experiments, a second stimulating electrode was placed in stratum radiatum near the subiculum and used to evoke responses in a control pathway that did not receive pattern stimulation. The recording electrode, a glass micropipette (1-6 M $\Omega$ ) pulled from thin-wall tubing $(1 \times 0.75 \mathrm{~mm})$ and filled with ACSF, was positioned in stratum radiatum of CA1, $\sim 1 \mathrm{~mm}$ away from the point of stimulation. Field potentials were amplified $100 \times$, bandpass-filtered between $1 \mathrm{~Hz}$ and $1 \mathrm{kHz}$ by a differential AC amplifier (A-M Systems, Everett, WA), converted to digital units, and stored on a computer for off-line analysis. Baseline stimulation consisted of $100 \mu \mathrm{sec}$ diphasic, constant-current pulses delivered once every $30 \mathrm{sec}$ at an intensity sufficient to elicit an excitatory postsynaptic potential (EPSP) of $\sim 1 \mathrm{mV}$. It was common to observe changes in the EPSP waveform after application of high $\left[\mathrm{Ca}^{2+}\right]$ or high $\left[\mathrm{Mg}^{2+}\right]$ medium. In these instances, the stimulation intensity was readjusted to yield a $1 \mathrm{mV}$ response. When normal medium was reintroduced to the slices, the stimulation intensity was reset to its original value.

High-frequency stimulation (HFS) (two bursts of 100 pulses at $100 \mathrm{~Hz}$, each burst separated by $10 \mathrm{sec}$ ) was used to induce LTP, whereas low-frequency stimulation (LFS) $(900$ pulses at $1 \mathrm{~Hz})$ was delivered to produce LTD or to reverse LTP. Where noted, brief bursts of LFS consisting of 30 pulses at $1 \mathrm{~Hz}$, with each burst separated by a $10 \mathrm{~min}$ baseline, were also used for LTP reversal. Pattern stimulation was delivered at baseline stimulation intensity, and stimulus timing was controlled by a computer.

Before administration of the first HFS or LFS episode, an initial baseline lasting anywhere from 15 to $30 \mathrm{~min}$ was collected, and the slope of the field EPSP $(\mathrm{mV} / \mathrm{msec})$ was determined. Slope magnitude was calculated as the difference between two cursors, separated by $1 \mathrm{msec}$, and placed on the middle portion of the descending phase of the EPSP. Because stimulation was set to evoke a $1 \mathrm{mV}$ response, no group differences for baseline EPSP slope were observed. To quantify changes in synaptic strength after pattern stimulation, 10 responses were collected at various times after termination of pattern stimulation and normalized to the average of the last $10 \mathrm{~min}$ of the initial baseline. Consequently, synaptic strength is expressed as percentage of baseline. The 10 normalized responses were then averaged for statistical comparison. As a group, aged animals exhibit greater variability in physiological parameters relative to adults (Geinisman et al., 1995). Thus, for experiments in which age comparisons were made, data from two to three slices per animal were pooled, and statistical analyses were conducted on animals rather than on slices. Repeated-measures ANOVA was applied to the means to determine differences across pattern stimulation sessions and differences between age groups. Post hoc analyses were conducted using Scheffe's F-test with significance set at $p<0.05$. Three aged and three adult animals failed to exhibit LTP of at least $10 \%$ and were excluded from the analysis.

\section{RESULTS}

Slices from aged rats exhibit homosynaptic LTD

Whether the CA3-CA1 synapse of the aged rat can express durable synaptic depression was examined by activating presynaptic fibers at $1 \mathrm{~Hz}$ for $15 \mathrm{~min}$ (LFS), and potential nonspecific changes in the slice preparation resulting from LFS were inspected by observing EPSPs collected from a second input (control) that received baseline stimulation only. After the LFS episode, responses gathered in each pathway were averaged at four different time points (10-15 $\mathrm{min}, 25-30 \mathrm{~min}, 40-45 \mathrm{~min}$, and 55-60 min post-LFS) and compared with the average of the responses recorded during the last $10 \mathrm{~min}$ of the initial baseline (pre-LFS). A significant effect of pathway $\left(F_{(1,32)}=16.8 ; p<\right.$ $0.01)$ and a difference across the various time points $\left(F_{(4,32)}=\right.$ $12.5 ; p<0.01)$ was found. A follow-up ANOVA revealed significant depression only in the test pathway $\left(F_{(4,24)}=26.65 ; p<\right.$ $0.001)$. Post hoc analyses showed that responses at each of the four post-LFS time points were significantly different from baseline but not from one another $(77 \pm 4 \%, 71 \pm 4 \%, 72 \pm 3 \%, 71 \pm$ $4 \%$; percentage of baseline), indicating that input-specific depression becomes stable in aged slices by $\sim 15$ min post-LFS and persists for at least $1 \mathrm{hr}$. The results of these experiments $(n=5)$ are illustrated in Figure 1.

The sensitivity of LTD at aged CA1 synapses to pharmacological antagonism of the NMDA receptor was explored by bathapplying AP5 $(50 \mu \mathrm{M})$ during LFS (LFS1). Washout of the drug was initiated shortly after LFS1, and a second round of 900 pulses (LFS2) was administered in normal medium (Fig. 2). A repeatedmeasures ANOVA indicated a significant effect of pattern stimulation $\left(n=5 ; F_{(4,19)}=4.58 ; p<0.03\right)$, and post hoc comparisons revealed a difference only between the baseline and LFS2, i.e., LFS after AP5 washout $(75 \pm 7 \%)$. Comparison of post-LFS1 responses recorded in AP5-containing medium $(91 \pm 7 \%$ at 30 min post-LFS1) with LTD recorded in slices that did not receive the drug (Fig. 1) further demonstrated that LTD-induction at aged synapses is impaired by AP5 $\left(F_{(1,19)}=7.39 ; p<0.03\right)$.

\section{Effects of altering the $\mathrm{Ca}^{2+} / \mathrm{Mg}^{2+}$ ratio on LTD induction}

A review of the literature suggests that susceptibility to LTD induction may depend on the $\mathrm{Ca}^{2+} / \mathrm{Mg}^{2+}$ ratio. When LTD has been observed in region CA1 of the adult, the extracellular $\mathrm{Ca}^{2+} / \mathrm{Mg}^{2+}$ ratio generally has exceeded 1.5 (Dunwiddie and Lynch, 1978; Dudek and Bear, 1992, 1993; however, see Wagner and Alger, 1995). In contrast, little or no LTD has been revealed in the adult when the $\mathrm{Ca}^{2+} / \mathrm{Mg}^{2+}$ ratio is closer to 1 (Fujii et al., 1991; Wexler and Stanton, 1993; O’Dell and Kandel, 1994). To investigate the influence of the $\mathrm{Ca}^{2+} / \mathrm{Mg}^{2+}$ ratio on LTD induction, synaptic responses from aged and adult slices were examined 15-20 min after delivery of LFS in normal medium $\left(2 \mathrm{mM} \mathrm{Ca}^{2+} / 2\right.$ $\mathrm{mM} \mathrm{Mg}^{2+}$ ) or in medium containing either $2 \mathrm{mM} \mathrm{Ca}^{2+} / 4 \mathrm{mM}$ $\mathrm{Mg}^{2+}$ (for aged slices) or $4 \mathrm{mM} \mathrm{Ca}{ }^{2+} / 2 \mathrm{mM} \mathrm{Mg}^{2+}$ (for adult slices). A summary of the findings is presented in Figure 6.

In normal medium, LFS depressed synaptic responses from aged animals $\left(75 \pm 6 \% ; F_{(5,11)}=16.1 ; p<0.02 ; n=6\right)$ but not from adults (101 $\pm 5 \% ; n=6)$ (Fig. 3 ), and a comparison between age groups demonstrated that the amount of depression observed was greater in aged rats $\left(F_{(1,11)}=10.808 ; p<0.01\right)$. Subsequent HFS was effective at reversing LTD and at inducing LTP in aged and adult animals, respectively (aged, $107 \pm 15 \%$; adult, $145 \pm$ $\left.11 \% ; F_{(1,9)}=20.661 ; p<0.001\right)$.

The effects of raising the bath $\left[\mathrm{Mg}^{2+}\right]$ on LTD induction for 
A

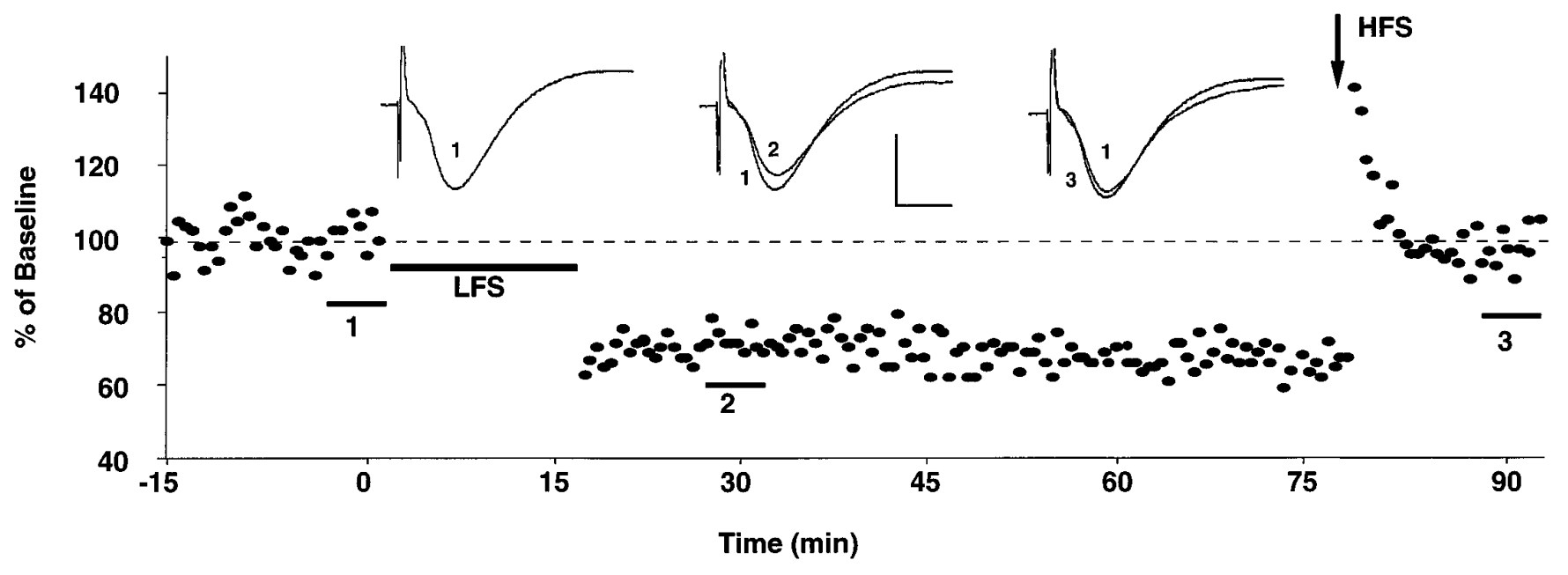

B

C
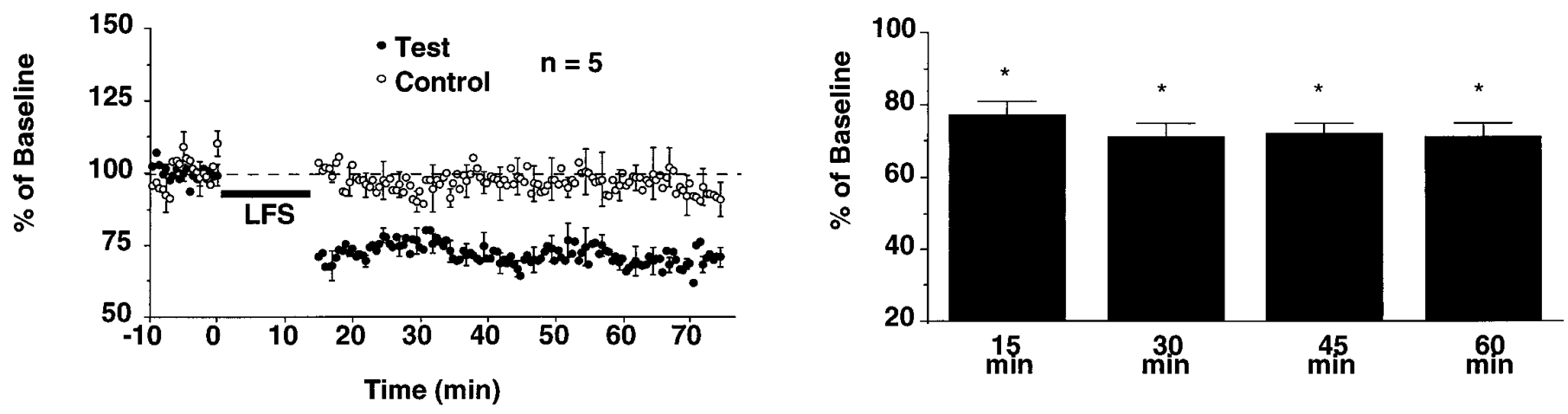

Figure 1. LTD in aged hippocampal slices is input-specific and durable. A, Plot of EPSP slopes (mean percentage of initial baseline) at CA3-CA1 synapses of an individual aged slice in response to stimulation of the Schaffer collaterals $(0.033 \mathrm{~Hz})$. LFS $(900$ pulses/1 Hz) resulted in a substantial depression of the EPSP slope, and this depression remained until presynaptic fibers were activated with HFS. Thin horizontal bars represent time points at which 10 successive EPSPs were averaged to generate representative waveforms. These average waveforms are depicted in the inset. Calibration for this figure and all subsequent figures: vertical $1 \mathrm{mV}$, horizontal $5 \mathrm{msec}$. $B$, Plot of EPSP slopes averaged across aged slices $(n=5)$ in which a test pathway (filled circles) underwent LFS, whereas a control pathway (open circles) received stimulation at baseline frequency only. The results show that LTD of aged slices is exclusive to the test pathway. Bars represent SEM. C, Responses recorded in the test pathway at 15, 30, 45, and 60 min after LFS were significantly different from the pre-LFS baseline but not from each other, demonstrating that LTD of aged slices is stable at 15 min post-LFS and persists for at least $1 \mathrm{hr}$. Bars represent SEM. Asterisk indicates difference from pre-LFS baseline $(p<0.05)$.

aged slices $(n=6)$ is depicted in Figure 4. The results demonstrated that LFS was ineffective at producing LTD under high $\mathrm{Mg}^{2+}$ conditions $(95 \pm 4 \%)$. Furthermore, aged slices bathed in high $\mathrm{Mg}^{2+}$ exhibited significantly less depression than aged slices perfused with normal medium $\left(F_{(1,13)}=8.005 ; p<0.02\right)$.

Conversely, raising the bath $\left[\mathrm{Ca}^{2+}\right]$ to $4 \mathrm{~mm}$ facilitated LTD induction in adult slices $\left(F_{(7,15)}=13.2 ; p<0.01 ; n=8\right)$. Post-LFS responses recorded in high $\mathrm{Ca}^{2+}(77 \pm 6 \%)$ were significantly different from post-LFS responses recorded in slices perfused with normal medium $\left(F_{(1,13)}=6.34 ; p<0.03\right)$ (Figs. 5, 6). For five other adult slices receiving high $\left[\mathrm{Ca}^{2+}\right]$, AP5 was added to the bath for 20-30 min before the first LFS episode (LFS1). AP5 washout was initiated shortly after LFS1, and responses were collected for an additional $30 \mathrm{~min}$ before delivery of a second LFS episode (LFS2) in AP5-free medium (Fig. 5B). A repeatedmeasures ANOVA for responses across the pre-LFS1 baseline, 15 min after LFS1 and 15 min post-LFS2, revealed a significant difference in synaptic strength across the various time points $\left(F_{(3,19)}=5.42 ; p<0.02\right)$. Post hoc analyses indicated that LTD in the presence of AP5 was impaired $(93 \pm 5 \%$ at 15 min postLFS1), and significant LTD was attained only after LFS2, i.e., after AP5 washout $(72 \pm 5 \%)$. Thus, LTD observed for adult slices under high $\mathrm{Ca}^{2+}$ conditions is sensitive to application of AP5.

\section{Reversal of LTP during aging}

The reversal of LTP was examined by applying the same 900 pulse LTD-inducing stimulation $60 \mathrm{~min}$ after induction of LTP in slices 


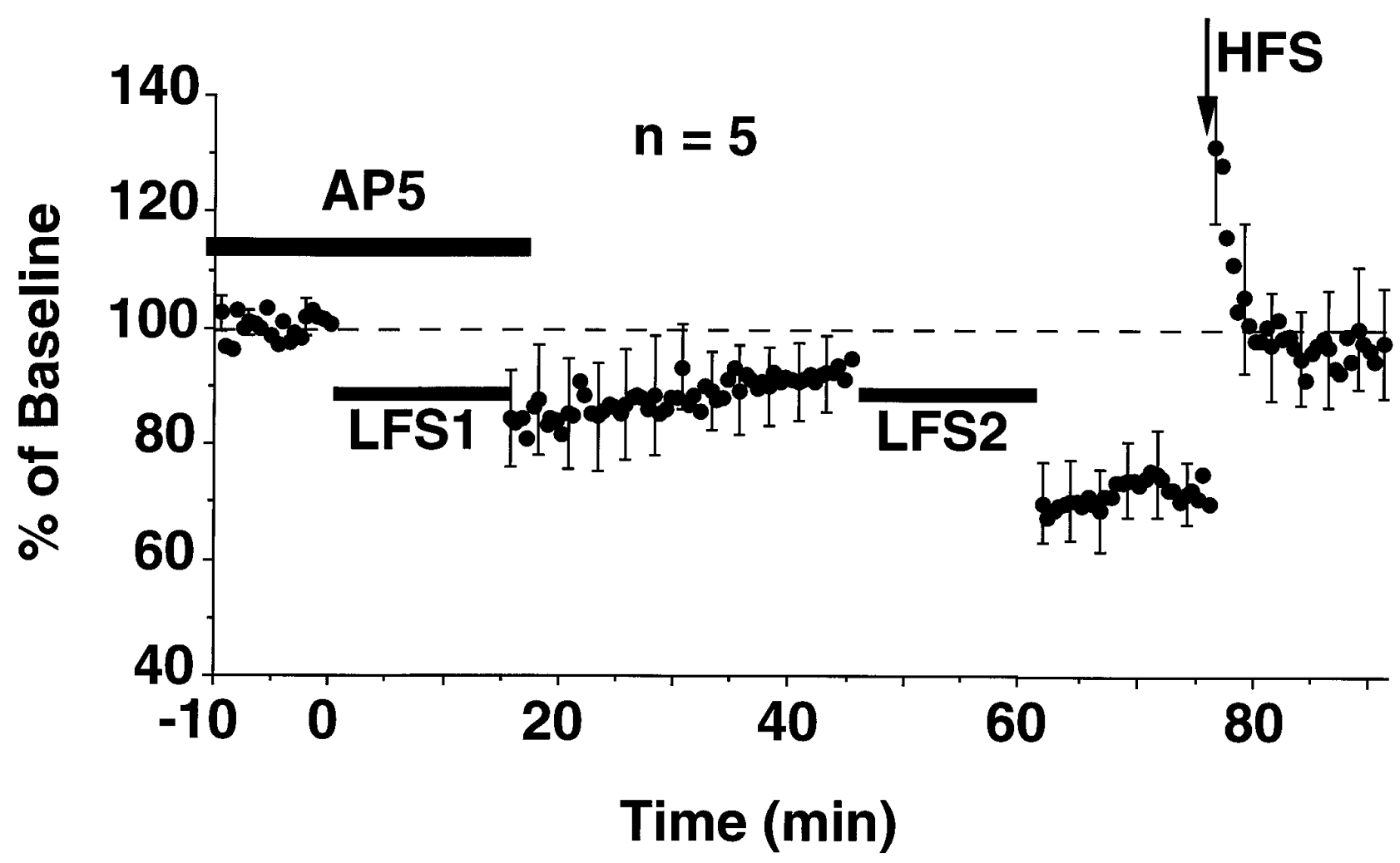

Figure 2. LTD in the aged rat exhibits sensitivity to AP5. For five aged slices, AP5 (thick horizontal bar) was bath-applied during the delivery of prolonged LFS (LFS1). After washout, LFS in drug-free medium (LFS2) was administered, and responses were followed for another 15 min before delivery of HFS. The results indicated that the ability of LFS to elicit LTD in area CA1 of the aged slice was impaired in the presence of AP5 and that significant LTD was attained only in drug-free medium. Bars represent SEM.

from aged $(n=8)$ and adult rats $(n=6)$ (Fig. 7). To test for potential age differences in LTP decay across the $1 \mathrm{hr}$ post-LTP time period, responses were averaged between 10-15 min and 55-60 min after LTP induction. A repeated-measures ANOVA indicated that LTP did decay somewhat between 15 and 60 min post-HFS1 $\left(F_{(1,12)}=\right.$ 6.57; $p<0.03$ ); however, no age effect was found in the magnitude of LTP or the extent of decay (aged, $149 \pm 14 \%$ at 15 min vs $142 \pm$ $11 \%$ at $60 \mathrm{~min}$; adult, $148 \pm 10 \%$ vs $140 \pm 9 \%$ ). When LFS was delivered $1 \mathrm{hr}$ after LTP induction, significant reversal was obtained for both groups $\left(F_{(1,12)}=11.08 ; p<0.01\right)$, and no age-related difference was observed in the magnitude of reversal. Although the response in aged animals after LFS was not different from the initial pre-HFS1 baseline (102 $\pm 8 \%)$, there was a tendency for adults to exhibit residual enhancement of the synaptic response (115 $\pm 7 \%$; $p=0.08)$. Responses from both age groups could be repotentiated similarly by a subsequent burst of HFS (HFS2) $\left(F_{(1,12)}=30.38\right.$; $p<0.001)$.

To determine whether the reversal of LTP is long-lasting, LFS was delivered 15 min after LTP induction and followed for $45 \mathrm{~min}$ (Fig. 8). The post-LFS response was not different from the preHFS1 baseline, and the response did not change during the $45 \mathrm{~min}$ recording period $(110 \pm 8 \%$ and $107 \pm 8 \%$ at 15 and $45 \mathrm{~min}$ post-LFS, respectively), demonstrating that LTP reversal in aged animals is long-lasting.

\section{Age-related differences in the susceptibility to LTP reversal}

Age-related differences in the susceptibility to LTP reversal were revealed by using six short-duration bursts (burst $=30$ pulses) of LFS to reverse previously induced LTP (Fig. 9). Each LFS burst was separated by $10 \mathrm{~min}$, and responses were averaged for the final $5 \mathrm{~min}$ of each post-LFS baseline and compared with the mean response 10-15 min after induction of LTP (HFS1). Although no difference in the magnitude of LTP was observed between aged $(n=9 ; 136 \pm$ $7 \%)$ and adult rats $(n=9 ; 140 \pm 6 \%)$, a significant effect of short-burst LFS on the reversal of $\operatorname{LTP}\left(F_{(6,96)}=34.38 ; p<0.01\right)$ and an LFS by age interaction $\left(F_{(6,96)}=2.46 ; p<0.05\right)$ were observed. Follow-up ANOVAs within each age group indicated a significant effect of LFS for both aged and adult rats $\left(F_{(6,62)}=9.88\right.$, $p<0.001$, and $F_{(6,62)}=15.2, p<0.001$, respectively). Post hoc comparisons, however, indicated that for aged slices, significant LTP reversal occurred after the first burst of LFS, whereas significant reversal was not observed for adults until after the fourth episode.

The extent of LTP reversal by short-duration bursts was examined by comparing the synaptic response after each LFS session with the pre-HFS1 baseline (aged: $F_{(6,62)}=9.83, p<0.001$; adult: $F_{(6,62)}=$ $15.2, p<0.001$ ). Post hoc comparisons revealed that responses from aged animals remained potentiated relative to the pre-HFS1 baseline only after the first and second session of LFS, whereas responses from adults remained significantly potentiated after every LFS session. Again, a subsequent burst of HFS (HFS2) increased the response relative to the final LFS session in both groups (aged, $126 \pm$ $9 \%$; adult, $\left.140 \pm 10 \% ; F_{(1,6)}=39.83 ; p<0.001\right)$, and no age difference was detected in the percentage of repotentiation obtained.

\section{LTP reversal in the aged rat is AP5-sensitive}

To examine the dependence of LTP reversal in aged slices $(n=6)$ on NMDA receptor activation, AP5 was bath-applied after the 


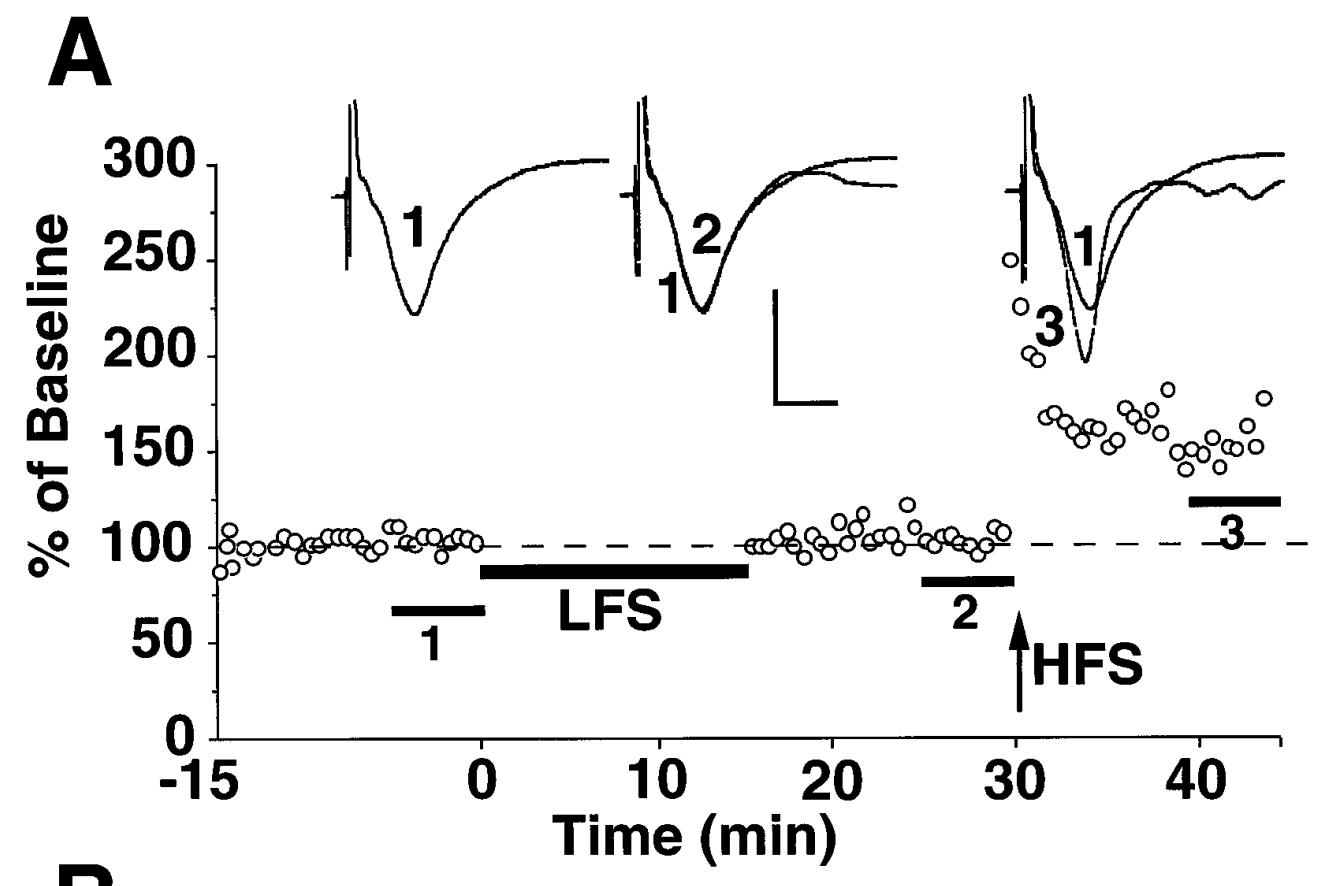

Figure 3. In normal medium, LTD is expressed in slices from aged but not adult rats. $A$, Plot of EPSP slopes for a single adult slice bathed in normal medium $\left(2 \mathrm{mM} \mathrm{Ca}^{2+} / 2 \mathrm{mM} \mathrm{Mg}^{2+}\right)$. LFS of Schaffer collaterals failed to depress the synaptic response, although a subsequent burst of HFS was able to instate LTP. Inset represents EPSP waveforms averaged at the indicated time points before and after pattern stimulation. $B$, Average data for slices from six aged rats and six adult rats. All slices were perfused with normal medium. LFS produced a substantial depression of aged CA3-CA1 synaptic responses ( filled circles), whereas slices from adults (open circles) showed no signs of LTD. HFS reversed LTD and induced LTP in aged and adult rats, respectively. Bars represent SEM.

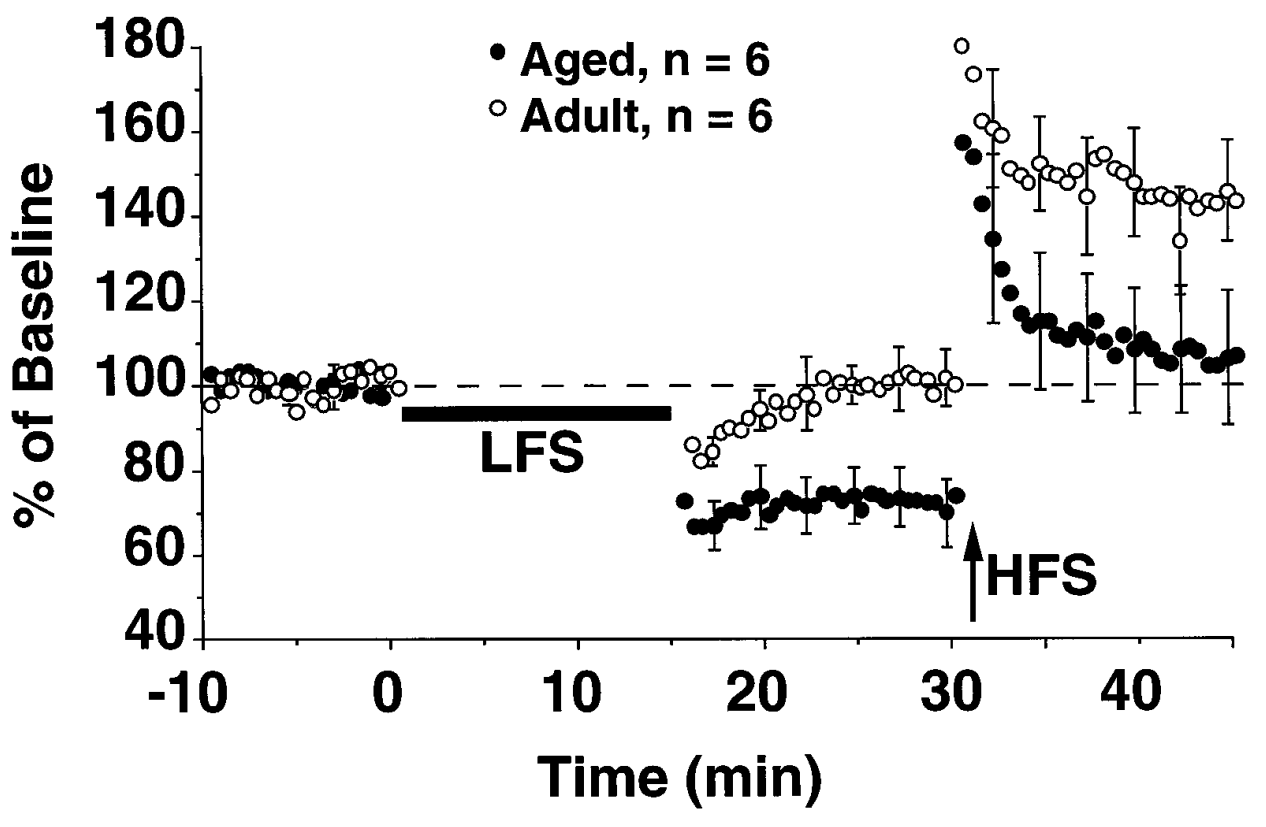

induction of LTP (HFS), 20-30 min before the delivery of LFS (LFS1) (Fig. 10). Drug washout was initiated after the LFS1 episode, and responses were collected in drug-free medium for 20-30 min before a second round of LFS (LFS2) was delivered. A repeated-measures ANOVA for response averages 15-20 min after HFS, 15-20 min after LFS1, and 10-15 min post-LFS2 revealed a significant difference in synaptic strength across the various time points $\left(F_{(2,17)}=9.08 ; p<0.01\right)$. No difference in the response between LFS during AP5 application and LTP (HFS, $145 \pm 9 \%$ vs LFS1, $138 \pm 12 \%$ ) was found; however, responses recorded after LFS2 $(121 \pm 13 \%)$ were significantly different from those after LFS1 and HFS. In addition, a significant difference between the post-LFS2 response average and the pre-HFS baseline was not observed.

\section{DISCUSSION}

The main conclusion of the present study is that aged rats are more susceptible to LTD and LTP reversal than are adults. Previous reports indicate that the percentage of LTD elicited by LFS is decreased in mature animals relative to neonates (Dudek and Bear, 1992, 1993; Mulkey and Malenka, 1992; Wexler and Stanton, 1993; Wagner and Alger, 1995). Moreover, some laboratories have failed to observe LTD in area CA1 of the adult animal (Fujii et al., 1991; O'Dell and Kandel, 1994). In contrast to adults, aged rats exhibit robust LTD at CA3-CA1 synapses that is persistent, input-specific, and reversible. Induction of LTD in aged slices was impaired in the presence of AP5 when compared both to the pre-LFS baseline and to LTD obtained in slices that 


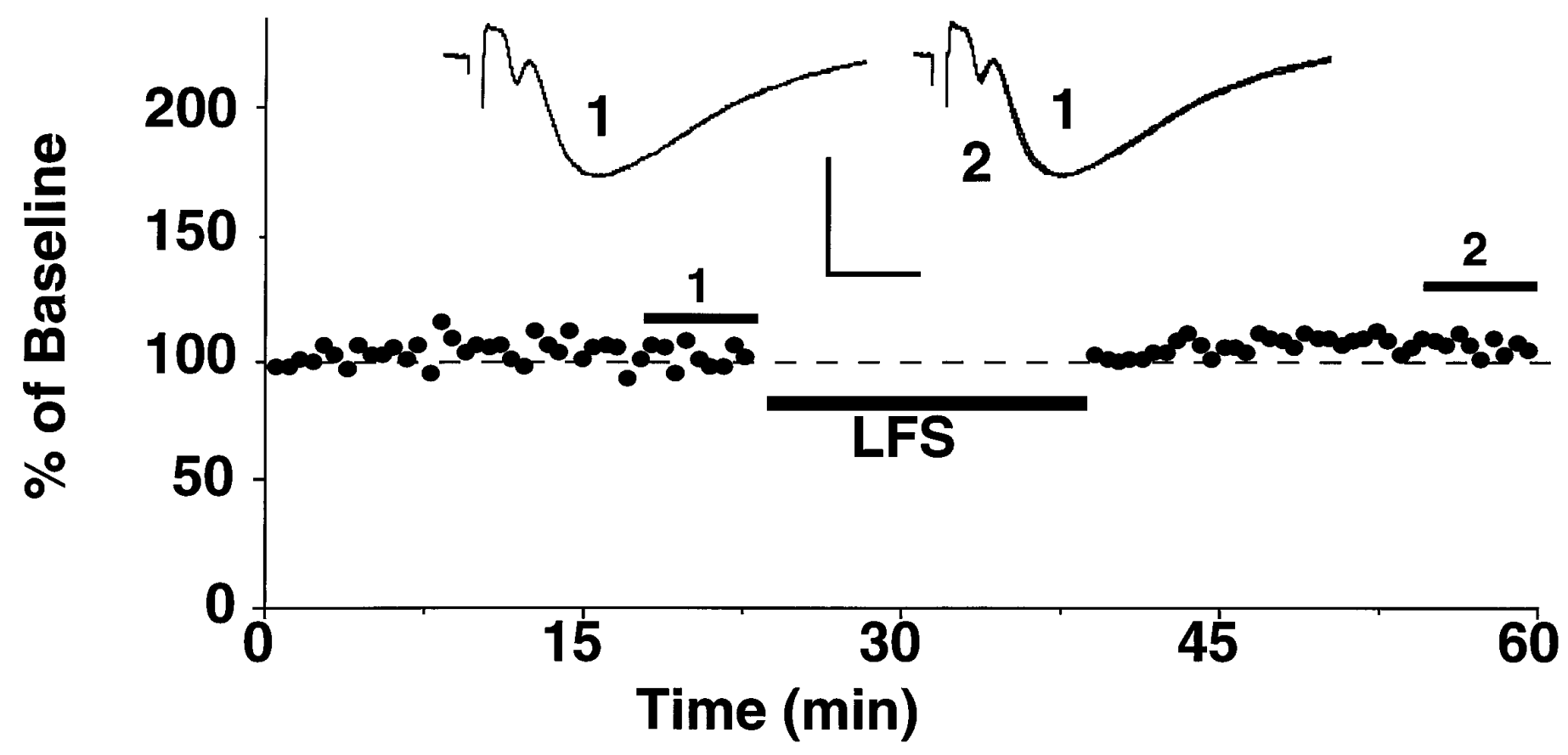

Figure 4. LTD in slices from aged rats is blocked when the bath $\left[\mathrm{Mg}^{2+}\right]$ is increased. $A$, Plot of EPSP slopes recorded in an individual aged slice bathed in high $\mathrm{Mg}^{2+}$ medium $\left(2 \mathrm{mM} \mathrm{Ca}^{2+} / 4 \mathrm{mM} \mathrm{Mg}^{2+}\right)$. Inset represents EPSP waveforms averaged at the indicated time points before and after LFS. Stimulation that markedly depressed CA1 synaptic responses in aged slices in previous experiments (Figs. 1-3) failed to do so when delivered in the presence of high $\left[\mathrm{Mg}^{2+}\right]$ media.

did not receive the drug. The small, although nonsignificant, depression observed in AP5-containing medium suggests a possible AP5-insensitive component, because full blockade of LTD and LTP reversal are observed in younger animals using similar or lower drug concentrations (Mulkey and Malenka, 1992; Maccaferri et al., 1994; O'Dell and Kandel, 1994).

Wagner and Alger (1995) suggest that developmental differences in LTD induction result from maturation of inhibitory mechanisms, which in turn modulate NMDA receptor function. Although inhibition in area CA1 increases across maturation (Dunwiddie, 1981; Michelson and Lothman, 1989; Muller et al., 1989; Swann et al., 1989), GABA $A_{A}$ function in the hippocampus of aged rats is unaltered or increased relative to that of adults (Landfield and Lynch, 1977; Lippa et al., 1981; Wenk et al., 1991; Billard et al., 1995; Griffith and Murchison, 1995). For some rat strains, however, the slower $\mathrm{GABA}_{\mathrm{B}}$-mediated postsynaptic inhibition of pyramidal cells is decreased during aging (Billard et al., 1995), which could influence NMDA receptor kinetics (Alger, 1991).

Furthermore, LTD is a $\mathrm{Ca}^{2+}$-dependent process (Mulkey and Malenka, 1992), and as such, susceptibility differences may arise from age-related alterations in $\mathrm{Ca}^{2+}$ regulation. There is mounting evidence demonstrating age-related changes in processes activated by $\mathrm{Ca}^{2+}$ influx attributable to CA1 neural activity (Landfield and Pitler, 1984; Pitler and Landfield, 1990; Moyer and Disterhoft, 1994), and postsynaptic $\mathrm{Ca}^{2+}$-dependent processes activated by LFS may be more sensitive to alterations in the extracellular $\mathrm{Ca}^{2+} / \mathrm{Mg}^{2+}$ ratio in aged animals (Landfield et al., 1986). A small increase in $\mathrm{Ca}^{2+}$ influx or increased activity of $\mathrm{Ca}^{2+}$-dependent second-messenger processes could alter susceptibility to LTD induction (Mulkey and Malenka, 1992; Mulkey et al., 1993; O’Dell and Kandel, 1994).

Studies that have observed LTD at adult synapses have gener- ally used an extracellular $\mathrm{Ca}^{2+} / \mathrm{Mg}^{2+}$ ratio $>1.5$ (Dunwiddie and Lynch, 1978; Dudek and Bear, 1992, 1993; however, see Wagner and Alger, 1995), whereas those studies that have used a $\mathrm{Ca}^{2+}$ / $\mathrm{Mg}^{2+}$ ratio closer to 1 have elicited little or no LTD in adults (Fujii et al., 1991; Wexler and Stanton, 1993; O’Dell and Kandel, 1994). The inability to induce LTD at adult synapses in the present study was overcome by increasing the $\mathrm{Ca}^{2+} / \mathrm{Mg}^{2+}$ ratio in the bath, and LTD induction in aged slices was prevented by administering LFS in the presence of high $\left[\mathrm{Mg}^{2+}\right]$ medium. Together, the results suggest that variance in the $\mathrm{Ca}^{2+} / \mathrm{Mg}^{2+}$ ratio may be responsible for discrepancies within the literature regarding the ability to induce LTD in adults and that an age-related difference in $\mathrm{Ca}^{2+}$ regulation may contribute to the increased susceptibility to induction of LTD in area CA1 of aged rats.

Despite controversy concerning LTD induction, the ability of prolonged LFS to depress previously potentiated CA1 synapses of adults in vitro is reported consistently throughout the literature (Barrionuevo et al., 1980; Staubli and Lynch, 1990; Fujii et al., 1991; Dudek and Bear, 1993; Wexler and Stanton, 1993; O’Dell and Kandel, 1994; Wagner and Alger, 1995). Therefore, it was not surprising that despite the difficulty of inducing LTD at naive adult synapses, LTP reversal was observed readily for both adult and aged animals (Fig. 7). The present study is consistent with the work of several researchers who describe a similar magnitude of LTP at aged and adult CA1 synapses (Landfield et al., 1978; Deupree et al., 1991; Moore et al., 1993) and demonstrate that in addition to LTP, another form of synaptic plasticity, LTP-reversal, remains intact during aging.

In the present study, prolonged $1 \mathrm{~Hz}$ stimulation delivered $1 \mathrm{hr}$ after LTP induction resulted in complete LTP reversal for aged rats. Although no age difference was observed, some residual potentiation remained at adult synapses, suggesting that age- 


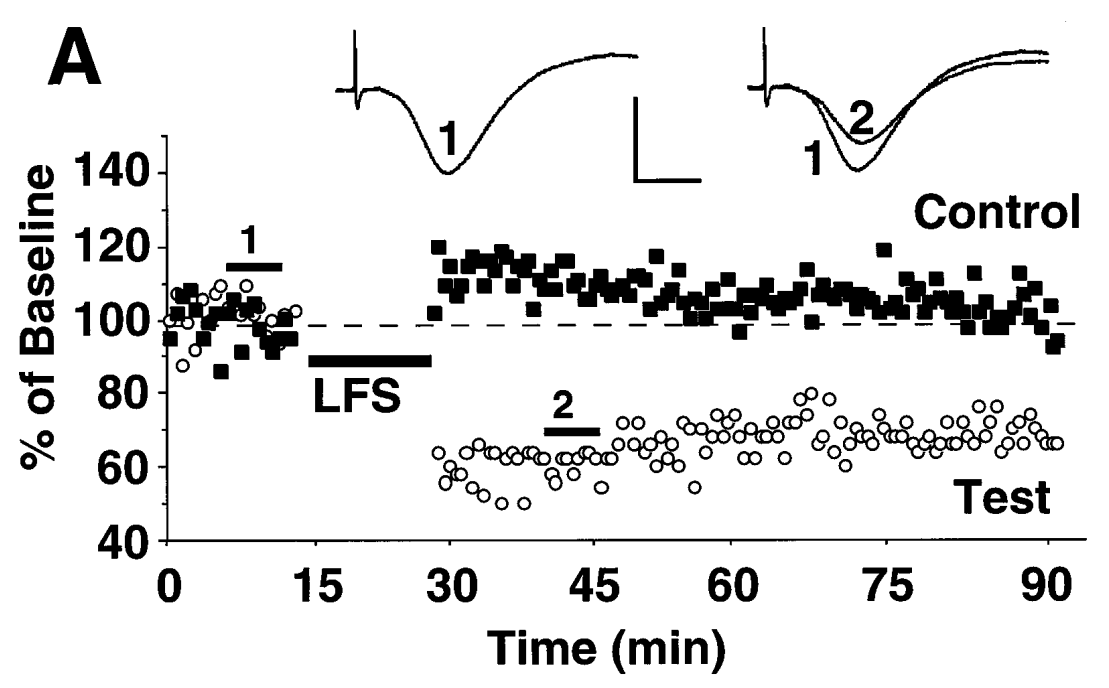

Figure 5. AP5-sensitive LTD in adult slices is revealed when the bath $\left[\mathrm{Ca}^{2+}\right]$ is increased. $A$, Plot of EPSP slopes recorded in a test (open circles) and a control pathway (filled squares) of an individual adult slice bathed in high $\mathrm{Ca}^{2+}$ medium $\left(4 \mathrm{mM} \mathrm{Ca}^{2+} / 2 \mathrm{mM} \mathrm{Mg}^{2+}\right)$. After the LFS episode, LTD was observed only in the test pathway. Inset represents EPSP waveforms averaged at the indicated time points before and after LFS. $B$, Data collected from an adult slice (in high $\mathrm{Ca}^{2+}$ ) that was perfused with AP5 (thick horizontal bar) during LFS (LFS1). After AP5 washout, another round of LFS (LFS2) was delivered. LTD was observed only after LFS2 (i.e., LFS in AP5-free medium). The depressed response could be potentiated by HFS to the initial baseline level.

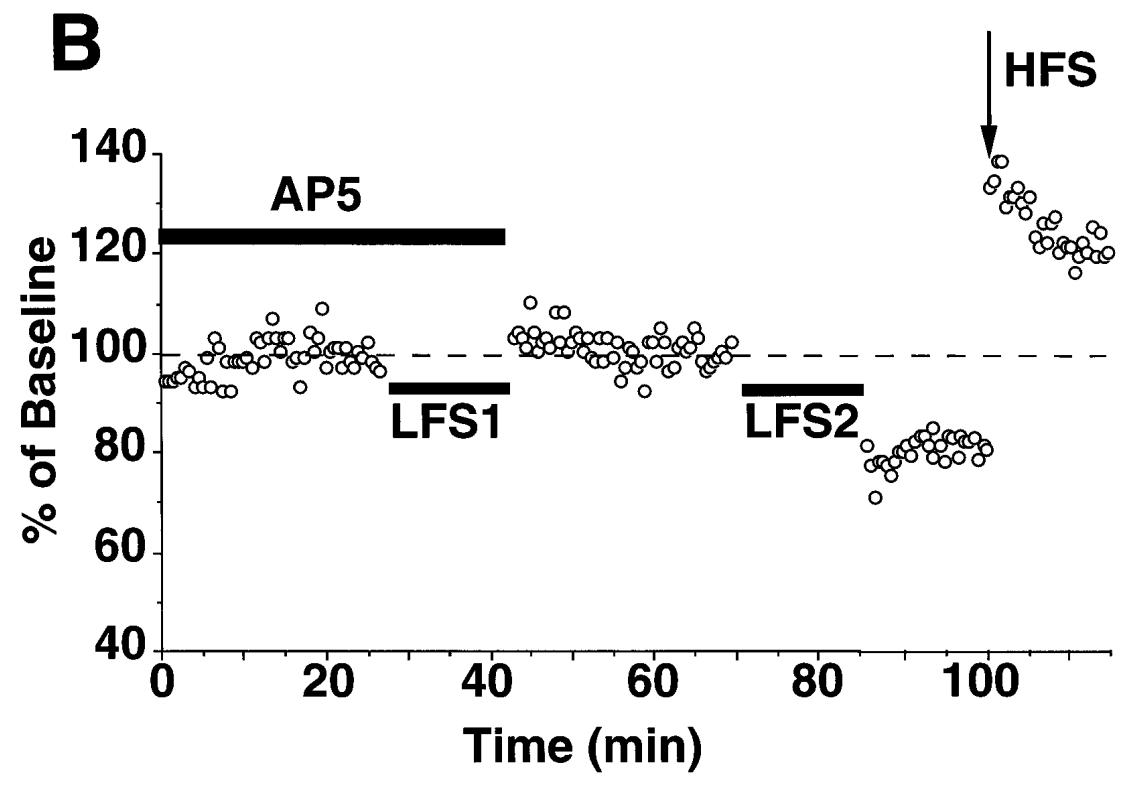

related differences might be revealed by using stimulation parameters near the threshold for LTP reversal. One way in which susceptibility to synaptic depression can be examined is by reducing the number of LFS pulses (Fujii et al., 1991; Mulkey and Malenka, 1992). When short-duration bursts of LFS were used to reverse LTP in the present study (Fig. 9), a marked age difference was revealed. Indeed, aged slices exhibited LTP reversal after the first set of LFS and complete reversal after the third set, whereas responses from adults failed to display significant reversal until after the fourth LFS episode. The results demonstrate that relative to adults, aged animals exhibit increased susceptibility to the reversal of LTP.

Previous research suggests that frequencies beyond 1-2 Hz may represent a threshold for synaptic depression and thus differences in susceptibility may also be examined using higher stimulation frequencies (Fujii et al., 1991; Dudek and Bear, 1992). An early study by Landfield et al. (1978) noted that a 5 min burst of $4 \mathrm{~Hz}$ stimulation delivered $30 \mathrm{~min}$ after LTP induction resulted in a large, stable depression of potentiated responses for CA1 synapses of aged but not adult rats. It therefore would be instructive

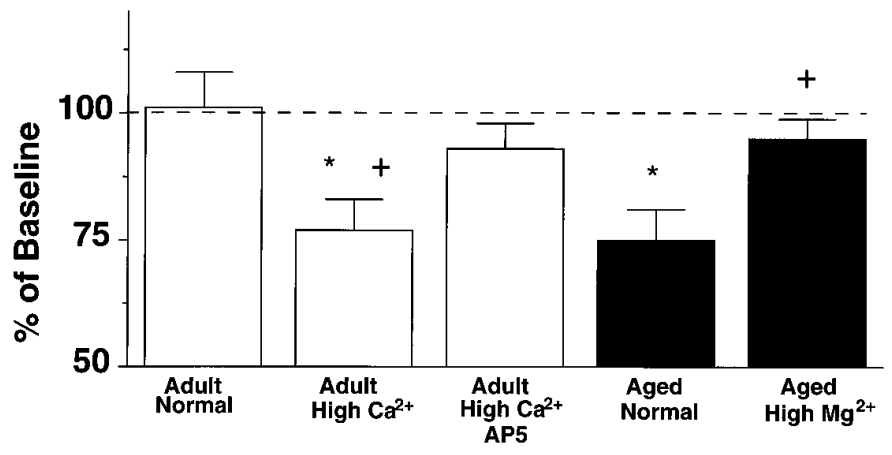

Figure 6. Statistical summary of the experiments illustrated in Figures $3-5$. In adult slices (open columns), LTD was nonexistent in normal medium and enhanced in high $\mathrm{Ca}^{2+}$ medium. LTD obtained under high $\mathrm{Ca}^{2+}$ conditions for the adult was inhibited by AP5. For aged slices ( filled columns), LTD was robust in normal medium but impaired when the bath $\left[\mathrm{Mg}^{2+}\right]$ was elevated to $4 \mathrm{~mm}$. Asterisk indicates a difference from the initial baseline; plus sign indicates a within-age group difference obtained between slices perfused with altered medium (high $\left[\mathrm{Ca}^{2+}\right]$ or $\left[\mathrm{Mg}^{2+}\right]$ ) and slices perfused with normal medium $(p<0.05)$. Bars represent SEM. 


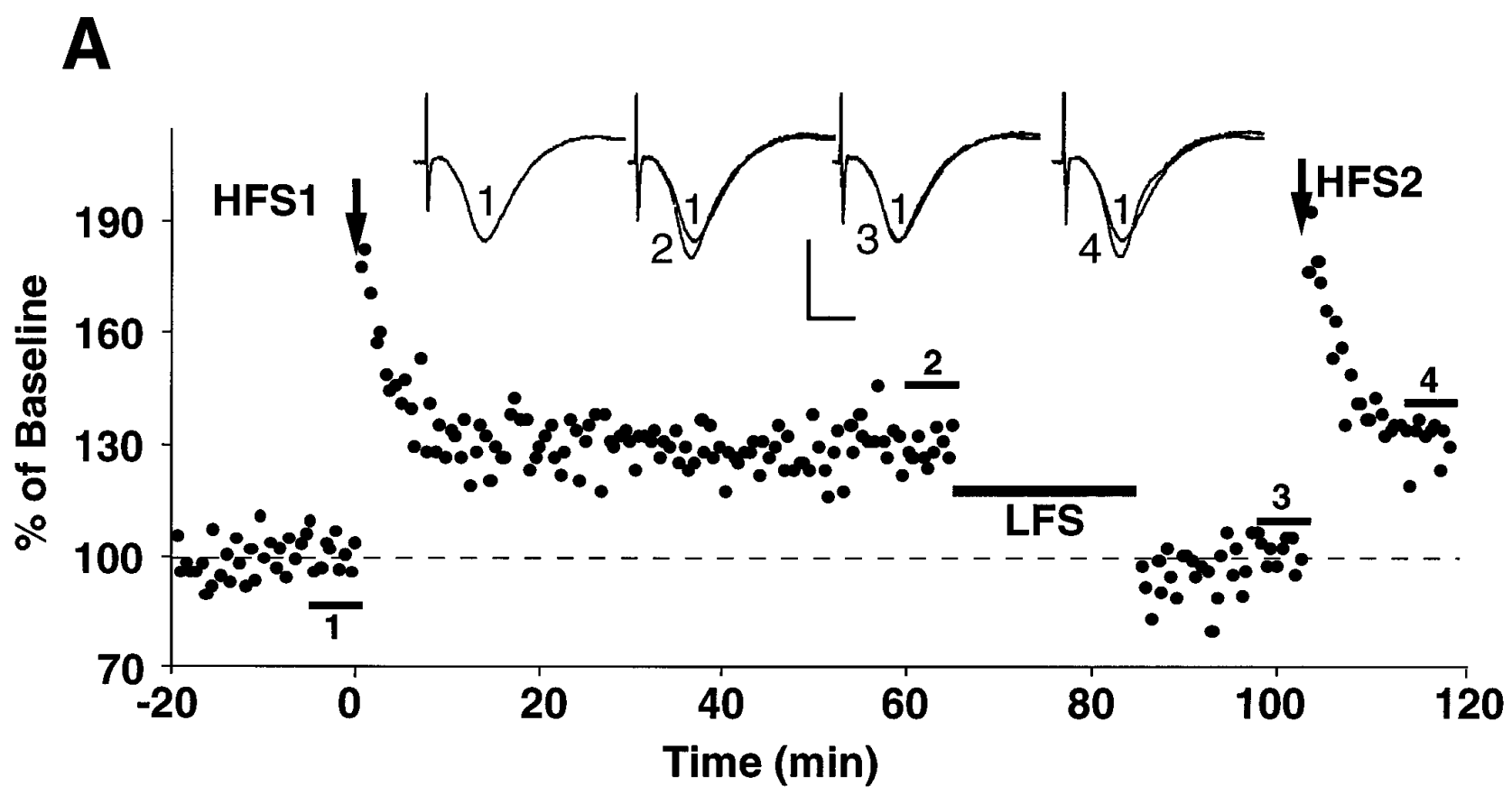

B

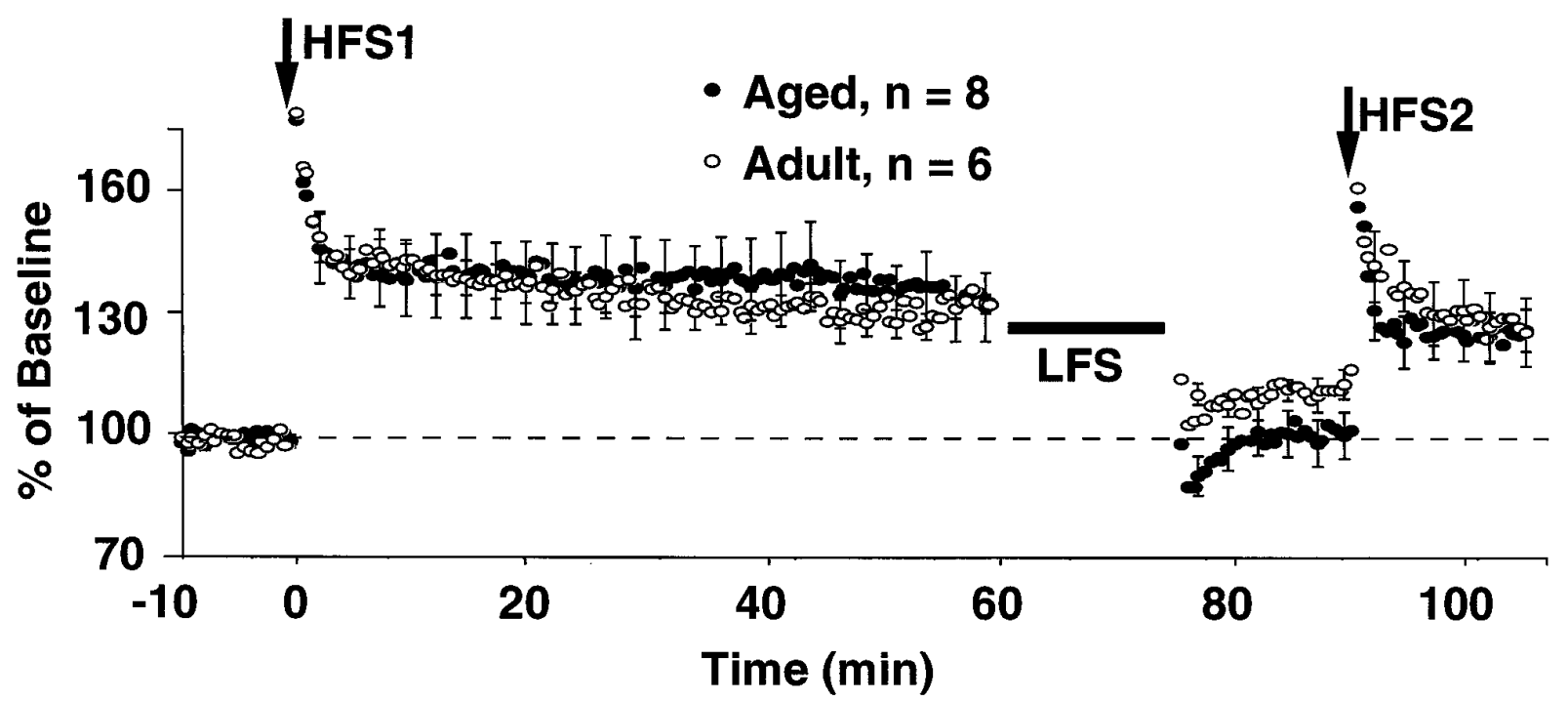

Figure 7. LTP reversal in area CA1 of aged and adult rats. $A$, Plot of EPSP slopes for an individual slice obtained from an aged rat. HFS (HFS1) was used to induce LTP, followed 60 min later by LTP-reversal (LFS, 900 pulses/1 Hz). LFS was followed 15 min later by repotentiation (HFS2). Inset represents EPSP waveforms averaged at the indicated time points before and after pattern stimulation. In this slice, LFS reversed LTP to the pre-HFS level, and a subsequent burst of HFS reinstated the potentiated response. B. Average data for slices from aged ( filled circles; $n=8)$ and adult (open circles; $n=6)$ animals. HFS1 produced similar LTP in both age groups. The potentiated response was also reversed to a similar level by LFS, although adults tended to exhibit residual potentiation. As well, repotentiation attributable to a second episode of HFS (HFS2) was not different between aged and adult rats. Bars represent SEM.

for future studies to include stimulation frequencies other than 1 $\mathrm{Hz}$ (e.g., $0.5-5.0 \mathrm{~Hz}$ ) to examine age-related differences in susceptibility to synaptic depression.

Because mechanisms underlying LTD are suspected to interact with LTP mechanisms to regulate synaptic function (Bear and Malenka, 1994), increased susceptibility to LTD may underlie age-related changes in synaptic strength (Barnes et al., 1992) and the ability to induce persistent increases in synaptic efficacy. Aged animals studied in vivo require a greater number of induction sessions to reach the same maximal level of LTP as younger animals, and once LTP is established, the potentiated response decays more rapidly at aged synapses (Barnes and McNaughton, 


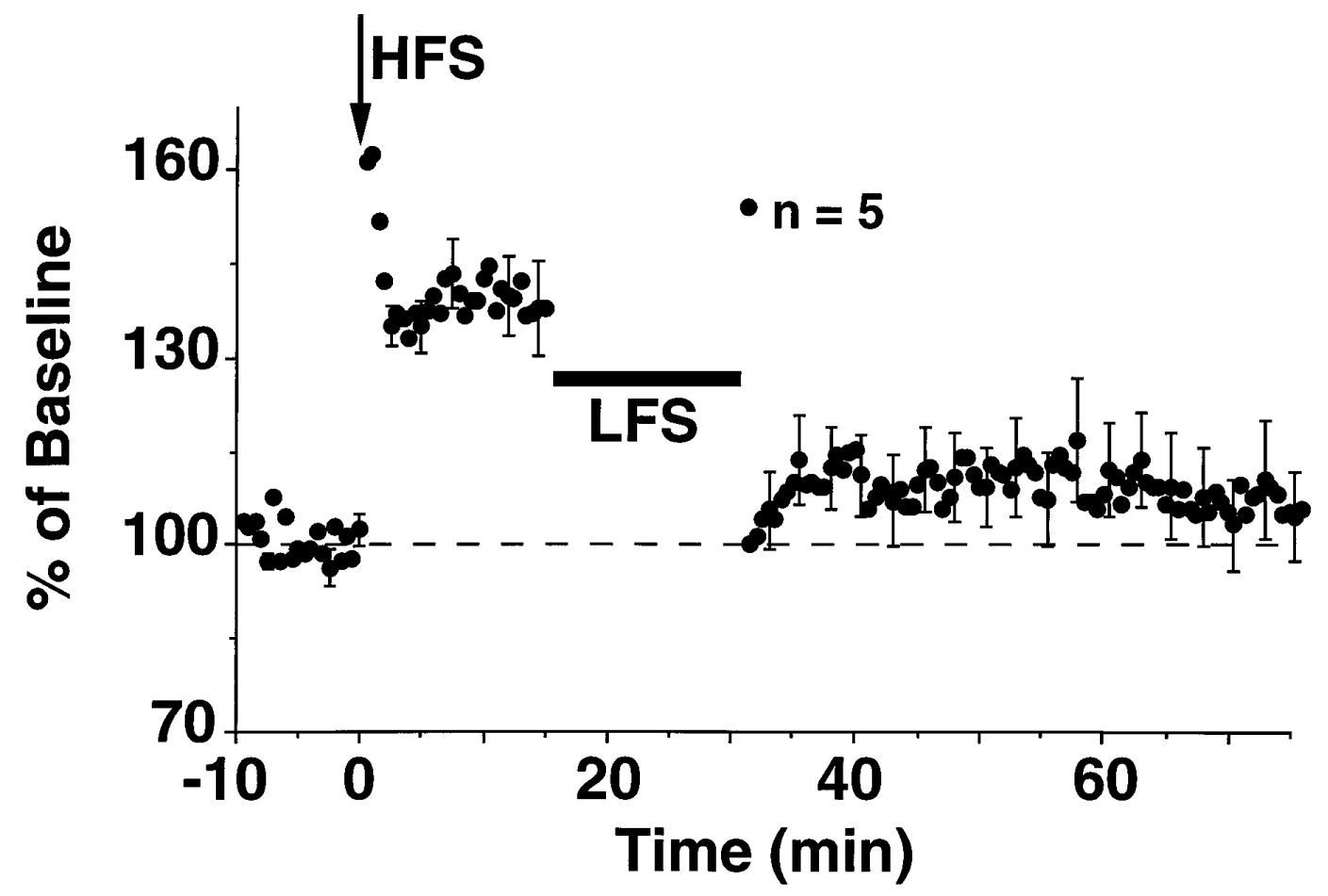

Figure 8. LTP reversal in aged slices is long-lasting. Average data for five aged slices in which LTP induction (HFS) was followed 15 min later by LFS. Post-LFS responses were not different from the pre-HFS baseline and remained stable for the duration of the experimental session (45 min). Bars represent SEM.

1985; deToledo-Morrell et al., 1988). Studies that have examined LTP maintenance and memory have demonstrated a relationship between rapid LTP decay in aged rats and forgetting on a spatial task (Barnes and McNaughton, 1985). If processes similar to LTD/LTP reversal contribute to the decay of LTP, then it is tempting to speculate that the increased rate of LTP decay observed in vivo for aged animals results from altered regulation of processes for resetting synaptic strength. As such, examination of the relationship between variability in memory performance and susceptibility to LTD might provide important information con-

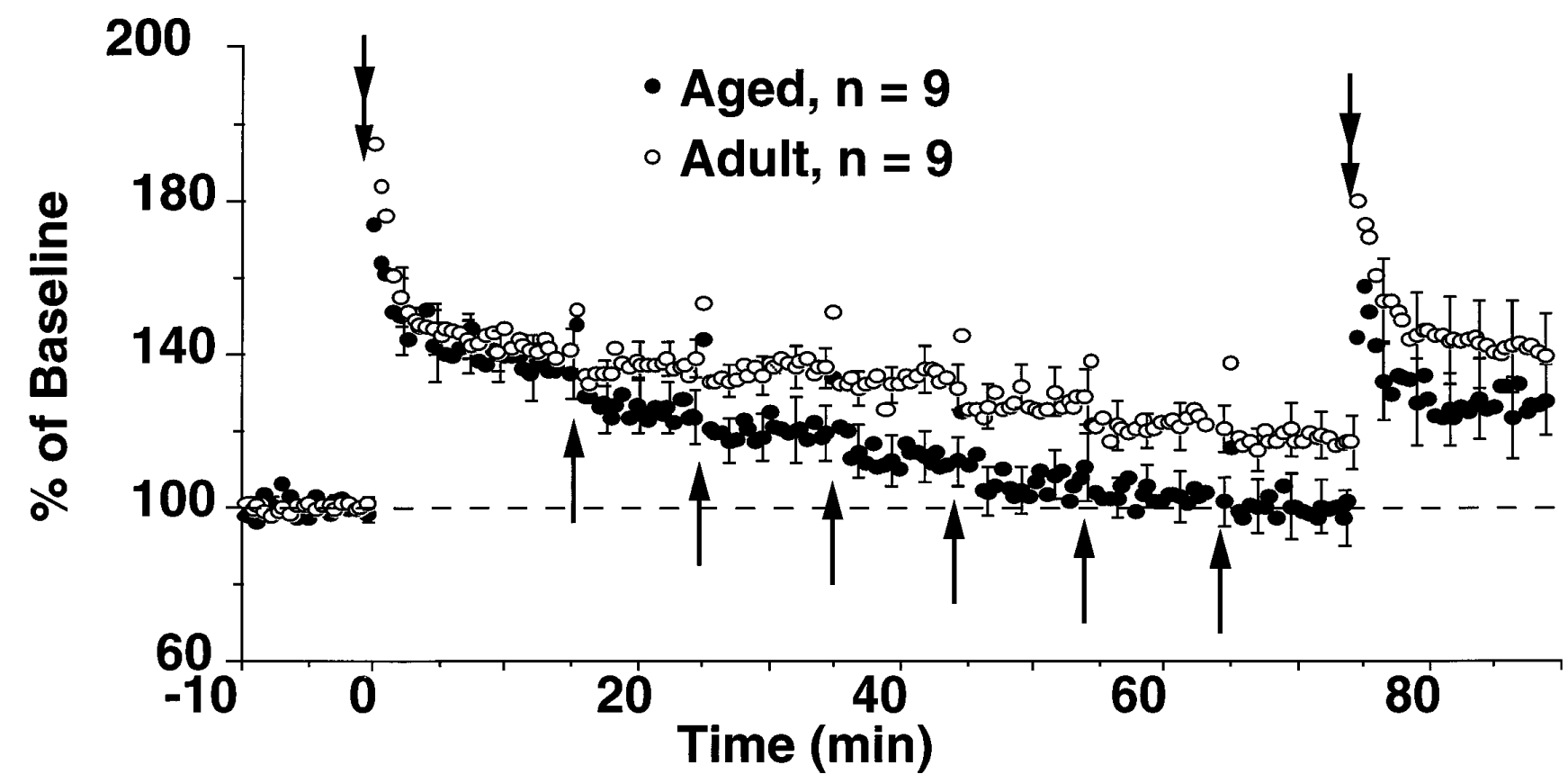

Figure 9. Aged animals are more susceptible to LTP reversal. Responses after induction of LTP (HFS1; double arrow) were similar in aged ( filled circles; $n=9$ ) and adult rats (open circles; $n=9)$. To reverse LTP, short-duration bursts (30 pulses) of LFS ( $1 \mathrm{~Hz}$; single arrows) were used. After the sixth episode of LFS, another bout of HFS (HFS2; double arrow) was administered. Aged rats exhibited LTP reversal sooner than adults, and the potentiated response in aged slices was reversed completely to pre-HFS1 levels by the third or fourth LFS episode. Bars represent SEM. 


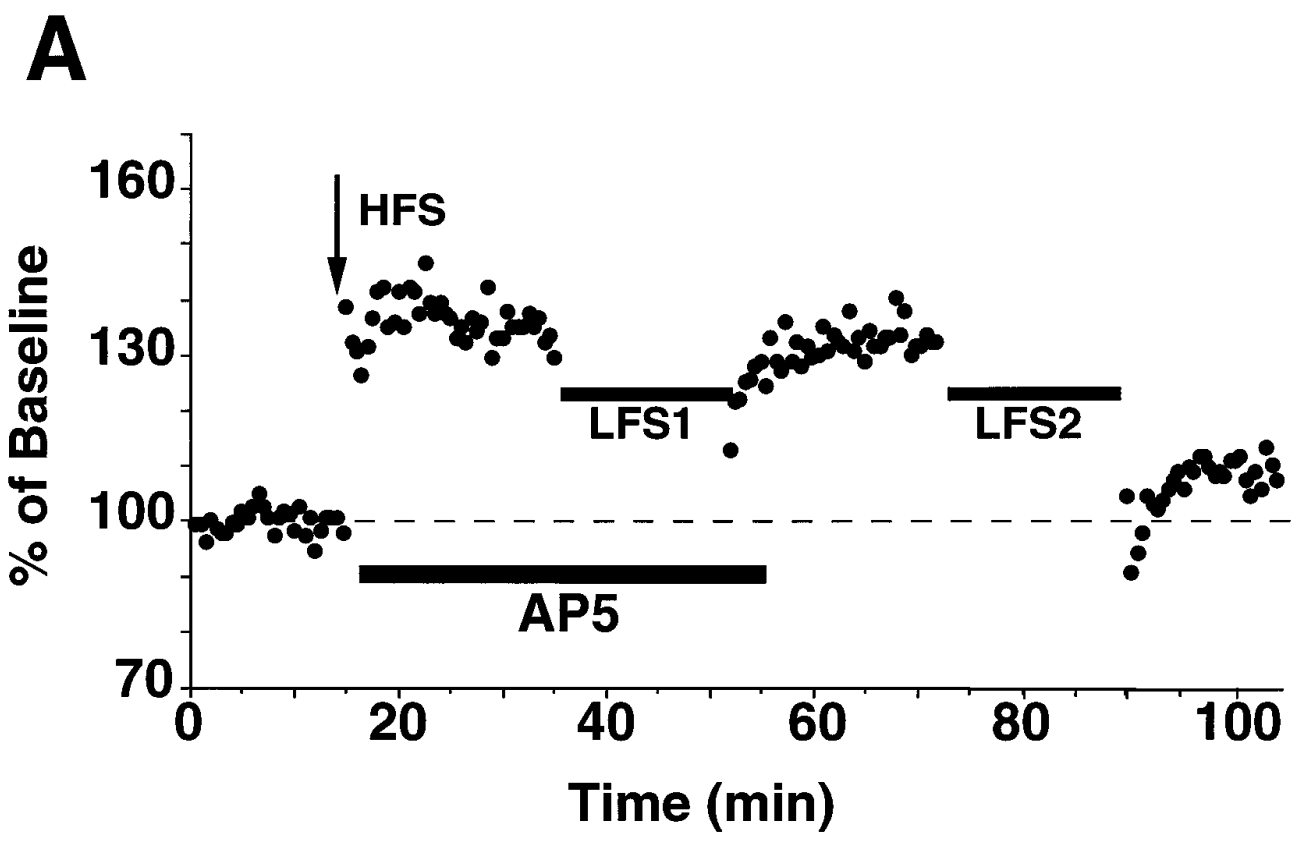

\section{B}

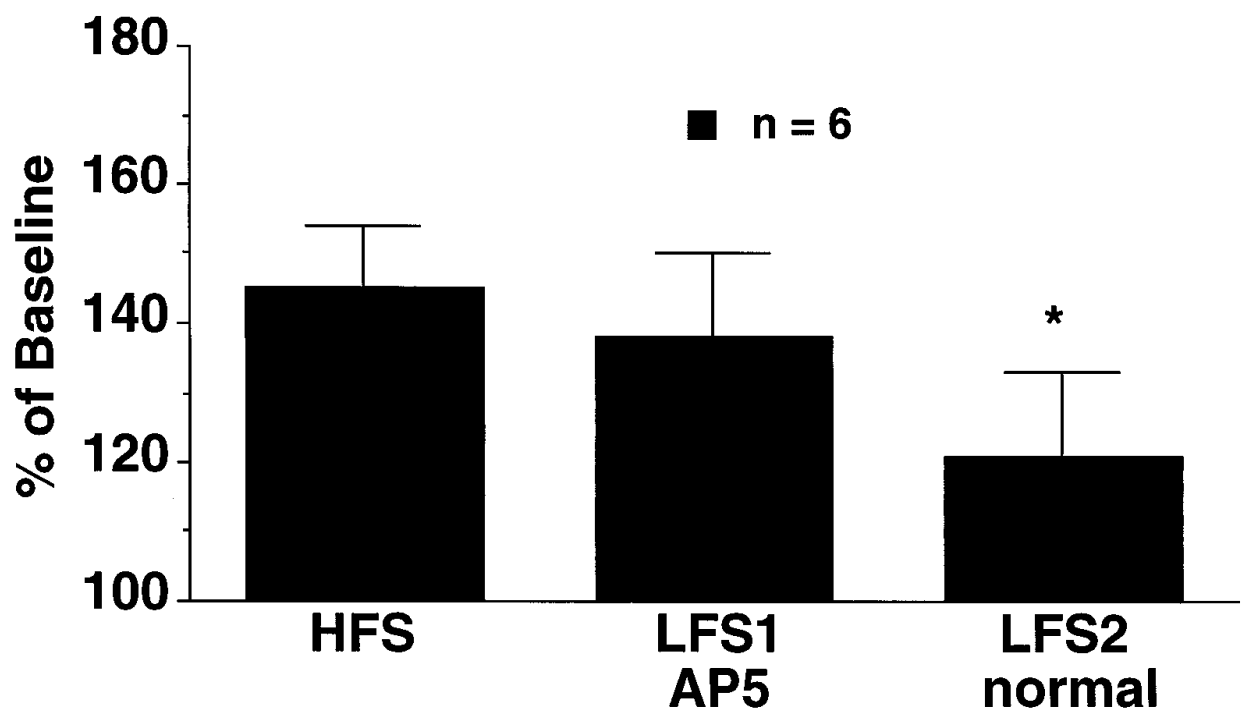

Figure 10. LTP reversal in aged slices is inhibited by AP5. A, Plot of EPSP slopes for an individual aged slice. LTP (HFS) was established, and AP5 was then introduced to the recording medium. No LTP reversal was observed when LFS was delivered in the presence of AP5 (LFS1). In drug-free media, however, a second episode of LFS (LFS2) resulted in substantial depression. $B$, Statistical summary for six aged slices in which LTP reversal was attempted in the presence of AP5. Asterisk indicates a difference between LFS2 and LFS1; $p<0.05$. Bars represent SEM.

cerning the mechanism by which information processed at hippocampal synapses is rapidly lost in aged animals (Foster et al., 1991; Barnes et al., 1994; Geinisman et al., 1995; Mabry et al., 1996).

\section{REFERENCES}

Alger BE (1991) Gating of GABAergic inhibition in hippocampal pyramidal cells. Ann NY Acad Sci 627:249-263.

Barnes CA, McNaughton BL (1985) An age comparison of the rates of acquisition and forgetting of spatial information in relation to long-term enhancement of hippocampal synapses. Behav Neurosci 99:1040-1048.

Barnes CA, Rao G, Foster TC, McNaughton BL (1992) Region-specific age effects on AMPA sensitivity: electrophysiological evidence for loss of synaptic contacts in hippocampal field CA1. Hippocampus 2:457-468.

Barnes CA, Treves A, Rao G, Shen J (1994) Electrophysiological markers of cognitive aging: region specificity and computational consequences. Semin Neurosci 6:359-367.

Barrionuevo G, Schottler F, Lynch G (1980) The effect of repetitive low frequency stimulation on control and potentiated synaptic responses in the hippocampus. Life Sci 27:2385-2391.
Bear MF, Malenka RC (1994) Synaptic plasticity: LTP and LTD. Curr Opin Neurobiol 4:389-399.

Billard JM, Lamour Y, Dutar P (1995) Decreased monosynaptic $\mathrm{GABA}_{\mathrm{B}}$-mediated inhibitory postsynaptic potentials in hippocampal CA1 pyramidal cells in the aged rat: pharmacological characterization and possible mechanisms. J Neurophysiol 74:539-546.

deToledo-Morrell L, Geinisman Y, Morrell F (1988) Age-dependent alterations in hippocampal synaptic plasticity: relation to memory disorders. Neurobiol Aging 9:581-590.

Deupree DL, Turner DA, Watters CL (1991) Spatial performance correlates with in vitro potentiation in young and aged Fischer 344 rats. Brain Res 554:1-9.

Dudek SM, Bear MF (1992) Homosynaptic long-term depression in area CA1 of the hippocampus and effects of $N$-methyl-D-aspartate receptor blockade. Proc Natl Acad Sci USA 89:4363-4367.

Dudek SM, Bear MF (1993) Bidirectional long-term modification of synaptic effectiveness in the adult and immature hippocampus. J Neurosci 13:2910-2918.

Dunwiddie TV (1981) Age-related differences in the in vitro rat hippocampus: development of inhibition and the effects of hypoxia. Dev Neurosci 4:165-175. 
Dunwiddie T, Lynch G (1978) Long-term potentiation and depression of synaptic responses in the rat hippocampus: localization and frequency dependency. J Physiol (Lond) 276:353-367.

Foster TC, Barnes CA, Rao G, McNaughton BL (1991) Increase in perforant path quantal size in aged F-344 rats. Neurobiol Aging 12:441-448.

Frey U, Krug M, Reymann KG, Matthies H (1988) Anisomycin, an inhibitor of protein synthesis, blocks late phases of LTP phenomena in the hippocampal CA1 region in vitro. Brain Res 452:57-65.

Fujii S, Saito K, Miyakawa H, Ito K, Kato H (1991) Reversal of longterm potentiation (depotentiation) induced by tetanus stimulation of the input to CA1 neurons of guinea pig hippocampal slices. Brain Res 555:112-122.

Geinisman Y, deToledo-Morrell L, Morrell F, Heller TE (1995) Hippocampal markers of age-related memory dysfunction: behavioral, electrophysiological and morphological perspectives. Prog Neurobiol 45:223-252.

Griffith WH, Murchison DA (1995) Enhancement of GABA-activated membrane currents in aged Fischer 344 rat basal forebrain neurons. J Neurosci 15:2407-2416.

Harris KM, Teyler TJ (1984) Developmental onset of long-term potentiation in area CA1 of the rat hippocampus. J Physiol (Lond) 346:27-48.

Jackson PS, Suppes T, Harris KM (1993) Stereotypical changes in the pattern and duration of long-term potentiation expressed at postnatal days 11 and 15 in the rat hippocampus. J Neurophysiol 70:1412-1419.

Landfield PW, Lynch G (1977) Impaired monosynaptic potentiation in in vitro hippocampal slices from aged, memory-deficient rats. J Gerontol 32:523-533.

Landfield PW, Pitler TA (1984) Prolonged $\mathrm{Ca}^{2+}$-dependent afterhyperpolarizations in hippocampal neurons of aged rats. Science 226:1089-1092.

Landfield PW, McGaugh JL, Lynch G (1978) Impaired synaptic potentiation processes in the hippocampus of aged, memory-deficient rats. Brain Res 150:85-101.

Landfield PW, Pitler TA, Applegate MD (1986) The effects of high $\mathrm{Mg}^{2+}$-to- $\mathrm{Ca}^{2+}$ ratios on frequency potentiation in hippocampal slices of young and aged rats. J Neurophysiol 56:797-811.

Linden DJ, Connor JA (1995) Long-term synaptic depression. Annu Rev Neurosci 18:319-357.

Lippa AS, Critchett DJ, Ehlert F, Yamamura HI, Enna SJ, Bartus RT (1981) Age-related alterations in neurotransmitter receptors: an electrophysiological and biochemical analysis. Neurobiol Aging 2:3-8.

Mabry TR, McCarty R, Gold PE, Foster TC (1996) Age and stresshistory effects on spatial performance in a swim task in Fischer-344 rats. Neurobiol Learn Memory 66:1-10.

Maccaferri G, Janigro D, Lazzari A, DiFrancesco D (1994) Cesium prevents maintenance of long-term depression in rat hippocampal CA1 neurons. NeuroReport 5:1813-1816.
Michelson HB, Lothman E (1989) An in vivo electrophysiological study of the ontogeny of excitatory and inhibitory processes in the rat hippocampus. Dev Brain Res 46:113-122.

Moore CI, Browning MD, Rose GM (1993) Hippocampal plasticity induced by primed burst, but not long-term potentiation, stimulation is impaired in area CA1 of aged Fischer 344 rats. Hippocampus 3:57-66.

Moyer JR, Disterhoft JF (1994) Nimodipine decreases calcium action potentials in rabbit hippocampal CA1 neurons in an age-dependent and concentration-dependent manner. Hippocampus 4:11-18.

Mulkey RM, Malenka RC (1992) Mechanisms underlying induction of homosynaptic long-term depression in area CA1 of the hippocampus. Neuron 9:967-975.

Mulkey RM, Herron CE, Malenka RC (1993) An essential role for protein phosphatases in long-term depression in area CA1 of the hippocampus. Science 261:1051-1055.

Muller D, Oliver M, Lynch G (1989) Developmental changes in synaptic properties in hippocampus of neonatal rats. Dev Brain Res 49:105-114.

Norris CM, Foster TC (1995) Aged rats show increased sensitivity to LTD-inducing stimulation. Soc Neurosci Abstr 21:433.17.

O'Dell TJ, Kandel ER (1994) Low-frequency stimulation erases LTP through and NMDA receptor-mediated activation of protein phosphatases. Learn Memory 1:129-139.

Otani S, Marshall CJ, Tate WP, Goddard GV, Abraham WC (1989) Maintenance of long-term potentiation in rat dentate gyrus requires protein synthesis but not messenger RNA synthesis immediately posttetanization. Neuroscience 28:519-526.

Pang K, Williams ML, Olton DS (1993) Activation of the medial septal area attenuates LTP of the lateral perforant path and enhances heterosynaptic LTD of the medial perforant path in aged rats. Brain Res 632:150-160.

Pitler TA, Landfield PW (1990) Aging-related prolongation of calcium spike duration in rat hippocampal slice neurons. Brain Res 508:1-6.

Staubli U, Lynch G (1990) Stable depression of potentiated synaptic responses in the hippocampus with $1-5 \mathrm{~Hz}$ stimulation. Brain Res 513:113-118.

Swann JW, Brady RJ, Martin DL (1989) Postnatal development of GABA-mediated synaptic inhibition in rat hippocampus. Neuroscience 28:551-561.

Wagner JJ, Alger BE (1995) GABAergic and developmental influences on homosynaptic LTD and depotentiation in rat hippocampus. J Neurosci 15:1577-1586.

Wenk GL, Walker LC, Price DL, Cork LC (1991) Loss of NMDA, but not GABA-A, binding in the brains of aged rats and monkeys. Neurobiol Aging 12:93-98.

Wexler EM, Stanton PK (1993) Priming of homosynaptic long-term depression in hippocampus by previous synaptic activity. NeuroReport 4:591-594. 